\title{
Refractive Outcomes of Four-Point Scleral Fixation of Akreos AO60 Intraocular Lens Using Gore-Tex Suture
}

\author{
Nimesh A Patel $\mathbb{B}^{\prime}$ \\ Kenneth C Fan' \\ Nicolas A Yannuzzi' \\ Jorge A Fortun' \\ Luis J Haddock' \\ Sonia $H$ Yoo $\mathbb{D}^{\prime}$ \\ Patrice J Persad (ID) \\ Elizabeth A Vanner (D) \\ Sarah P Read ${ }^{2}$ \\ Basil K Williams Jnr ${ }^{1,3}$ \\ Jayanth Sridhar' \\ Thomas A Albini' \\ Harry W Flynn Jnr (D) \\ Kendall Donaldson' \\ Justin $\mathrm{H}$ Townsend $\mathbb{D}^{\prime}$ \\ 'Department of Ophthalmology, Bascom \\ Palmer Eye Institute, University of Miami \\ Miller School of Medicine, Miami, FL \\ 33136, USA; ${ }^{2}$ Retina Consultants of \\ Hawaii, Aiea, HI, USA; ${ }^{3}$ Department of \\ Ophthalmology, University of Cincinnati \\ College of Medicine, Cincinnati, \\ $\mathrm{OH}, \mathrm{USA}$
}

This article was published in the following Dove Press journal: Clinical Ophthalmology

\begin{abstract}
Background/Objective: To determine the refractive outcomes after 4-point scleral fixation of the Akreos AO60 intraocular lens with Gore-Tex suture.

Methods: This was a single referral center, multi-surgeon, retrospective consecutive case series. A total of 63 eyes met the inclusion criteria for having received surgical implantation of the Akreos AO60 intraocular lens with Gore-Tex suture from August 2014 to December 2018. Exclusion criteria included all ocular pathology that precluded an accurate refraction, concurrent ocular surgery, poor corrected pre-operative visual potential, among other factors. Main outcome measures included post-operative uncorrected visual acuity (VA), best-corrected VA, and spherical equivalent deviation from target.

Results: Mean pre-operative BCVA was $0.67 \pm 0.64$ LogMAR (20/93 Snellen). Mean final post-operative BCVA was $0.17 \pm 0.18$ (20/28 Snellen) and mean final post-operative UCVA was $0.31 \pm 0.22$ (20/41 Snellen). Mean post-operative spherical equivalent was -0.57 D. Mean post-operative astigmatism was $0.85 \mathrm{D}$.

Conclusion: Refractive outcomes after secondary implantation with Akreos AO60 are favorable in eyes with good visual potential.
\end{abstract}

Keywords: Akreos AO60 lens, Gore-Tex, refractive outcomes secondary intraocular lens, scleral fixated IOL

\section{Introduction}

There is a growing body of techniques for secondary intraocular lens (IOL) placement in the absence of capsular support, including the 4-point fixation of the Akreos AO60 lens using Gore-Tex suture. ${ }^{1-5}$ Although there are multiple studies reporting short-term data with a favorable safety profile, there are few studies examining the refractive outcomes. ${ }^{3,5}$ A challenge in accurately assessing this has been the multiple ocular comorbidities that often exist in these cases, including history of open globe injury, retinal detachment, or ocular trauma, which may preclude an accurate refraction or affect the uncorrected visual acuity. ${ }^{2,4,6,7}$ In this study, we aim to study the refractive outcomes in eyes with good visual potential post-secondary IOL implantation.

\section{Methods}

This study was conducted in accordance with the ethical standards established in the 1964 Declaration of Helsinki for research involving humans and approved by the Institutional Review Board (IRB) of the University of Miami Miller School of
Correspondence: Justin H Townsend Email jtownsend@med.miami 
Medicine. This was a single-center, retrospective, multisurgeon, consecutive case series. The electronic medical record for all patients having received surgical implantation of the Akreos AO60 (Bausch \& Lomb, Rochester, NY) intraocular lens with Gore-Tex (W.L. Gore \& Associates, Newark, DE) suture from August 2014 to December 2018 were identified. Exclusion criteria included all ocular pathology that precluded an accurate refraction, concurrent cornea or glaucoma surgery with secondary IOL, no IOL calculation in the medical record, follow up less than 1 month, and no post-operative refraction. Patients were excluded if there was a known documented impairment for potential uncorrected visual acuity to be at least $20 / 30$.

Patient data collected included age, gender, surgeon, indication for surgery, lens status, prior medical and surgical ocular history, and number of follow-up days. Preoperative refractive data included best-corrected visual acuity (BCVA), refraction, and lens calculations performed using optical biometry (IOLMaster 700; Carl Zeiss Meditec, Dublin, CA). The implanted IOL lens power allowed extrapolation of the surgeon's target refraction in spherical equivalent based on Sanders-Retzlaff-Kraff theoretical (SRK/T) and Holladay formulas. Uncorrected visual acuity (UCVA) was used in the analysis if the absolute value of the target was between 0 and 1 diopters (D), or if cylinder was $<2$ diopters on IOL master preoperatively. The objective was to report UCVA outcomes for those with good UCVA potential at distance.

The approach to scleral fixation of Akreos AO60 lens with Gore-Tex suture has been previously described ${ }^{1,2}$ and was followed with several intra-operative modifications: surgeons' choice of the distance from limbus to sclerotomy site $(2.0 \mathrm{~mm}, 2.5 \mathrm{~mm}, 3.0 \mathrm{~mm})$, clear corneal versus scleral tunnel incision, and number and type of sutures for wound closure. The procedure is as follows: the surgeon is operating superiorly. A 180-degree marker is used to mark the horizontal midline (180 degrees axis). Two localized conjunctival peritomies created nasally and temporally. Four sclerotomies are made. Superior nasal and superior temporal sclerotomies are approximately $2.5 \mathrm{~mm}$ posterior to the limbus and $2.5 \mathrm{~mm}$ superior to the midline with a trocar blade. The inferior nasal and inferior temporal sclerotomies are fashioned approximately $2.5 \mathrm{~mm}$ posterior or to the limbus and $2.5 \mathrm{~mm}$ inferior to the midline with a 25 gauge MVR blade. Core vitrectomy is performed. The $8-0$ GoreTex sutures are passed first through the IOL haptics outside the eye and then the sutures are pulled through a $3.5 \mathrm{~mm}$ superior wound and retrieved through the sclerotomies on each side using forceps. The Bausch and Lomb Akreos A060 IOL is folded and placed through the corneal wound into the posterior chamber of the eye. The suture is tied in a 3-1-1 fashion temporally and then again nasally. The knots are then rotated and buried inside the sclera. ${ }^{2}$

Post-operative data included day 1 , month 3 , year 1 , and final best-corrected visual acuity as well as final uncorrected visual acuity (UCVA), final refraction, and any post-operative complications. Primary outcome measures included post-operative deviation from refractive target and change in astigmatism.

\section{Statistical Analysis}

Snellen visual acuity measurements were converted to logarithm of the minimum angle of resolution for analysis (LogMAR). A p-value of less than 0.05 was considered statistically significant for all tests. All tests were performed using SAS version 9.4 (SAS Institute Inc., Cary, NC, USA). After stratifying the dataset by each respective categorical variable of interest, PROC MEANS calculated descriptive statistics for the refractive outcome in each sub-group. The refractive outcome variable was not normally distributed. Thus, in analyses with continuous explanatory variables, Spearman's Rank-Order Correlation was the method of choice. The two-sample Mann-Whitney U, or Wilcoxon, test was the non-parametric method of choice in examining the association between each categorical variable and the outcome. A chi-square $\left(\chi^{2}\right)$ test was performed for comparing the difference in diagnosis of post-operative cystoid macular edema (CME) for those with or without OCT exam. Additionally, a sensitivity analysis was performed removing subjects with duration of follow-up of less than 6 weeks.

\section{Results}

We examined the medical records of 158 total patients over the study period and 63 eyes of 63 patients ( 42 males, 21 females) met the inclusion criteria with baseline characteristics summarized in Table 1. A significant portion of patients were excluded due to pre-operative retinal and corneal pathology. All causes for exclusion are summarized in Table 2. Median age was $62.2 \pm 14.3$ (range 36-91) years old, and age did not significantly affect refractive outcomes $(p=0.84)$. Mean follow-up was 226.5 days (range $27-883$ days) with median 185 days, and a lower quartile of 92 days. Length of follow-up did not significantly affect the refractive outcomes based on Spearman Rank-Order Correlation statistics $(p=0.94)$. Most common indications 
Table I Baseline Patient Demographics and Clinical History

\begin{tabular}{|l|l|}
\hline Characteristics & Data \\
\hline Age (years), mean \pm SD & $62.2 \pm 14.3$ \\
\hline & $\mathrm{P}=0.84$ \\
\hline Gender, no. (\%) & \\
Male & $42(66 \%)$ \\
\hline Follow-up time (days), mean (range) & $225(27-883)$ \\
\hline Indication for surgery, no. (\%) & \\
Subluxed/dislocated crystalline lens & $27(43 \%)$ \\
Subluxed/dislocated pseudophakic lens & $27(43 \%)$ \\
History of complicated cataract surgery & $4(6 \%)$ \\
Other & $5(8 \%)$ \\
\hline Ocular History, no. (\%) & \\
Trauma & $32(52 \%)$ \\
$\quad$ Male & 23 of $4 \mathrm{I}(56 \%)$ \\
$\quad$ Female & 9 of $2 \mathrm{I}(43 \%)$ \\
Retinal Detachment & $14(22 \%)$ \\
Ruptured Globe & $5(8 \%)$ \\
Glaucoma & $4(6 \%)$ \\
Pseudoexfoliation & $4(6 \%)$ \\
Corneal Pathology & $2(3 \%)$ \\
Severe myopia & $\mathrm{I}(2 \%)$ \\
Ectopia lentis & $\mathrm{I}(2 \%)$ \\
Marfan Syndrome & $\mathrm{I}(2 \%)$ \\
Uveitis & $\mathrm{I}(2 \%)$ \\
Diabetic retinopathy & $\mathrm{I}(2 \%)$ \\
Epiretinal membrane & $\mathrm{I}(2 \%)$ \\
Pigment dispersion syndrome & $\mathrm{I}(2 \%)$ \\
\hline
\end{tabular}

Note: Other indications for secondary lens implantation include retained lens fragment, loss of zonular support resulting in aphakia, or capsular bag complications. Abbreviations: SD, standard deviation; no., number.

for surgery included subluxed or dislocated crystalline lens (43\%), subluxed or dislocated pseudophakic lens $(43 \%)$, or history of complicated cataract surgery $(6 \%)$ as seen in

Table 2 Exclusion Criteria

\begin{tabular}{|l|l|}
\hline Exclusion Criteria & Count \\
\hline Concurrent glaucoma surgery & $3(8 \%)$ \\
History of DSAEK & $2(5 \%)$ \\
History of penetrating keratoplasty & $\mathrm{I}(3 \%)$ \\
Corneal scar with astigmatism & $10(26 \%)$ \\
Post-op retinal pathology & $2(5 \%)$ \\
Pre-op retinal pathology & $\mathrm{I}(33 \%)$ \\
Prior refractive surgery & $2(5 \%)$ \\
No post-op refraction & $\mathrm{I}(3 \%)$ \\
Lost to follow-up & $\mathrm{I}(3 \%)$ \\
No IOL calcs & $3(8 \%)$ \\
History of Trabeculectomy & $\mathrm{I}(3 \%)$ \\
\hline
\end{tabular}

Abbreviations: DSAEK, descemet's stripping automated endothelial keratoplasty; $\mathrm{IOL}$, intraocular lens.
Table 1. A history of trauma was noted in $23 / 41(56 \%)$ of males and $9 / 21(43 \%)$ of females.

The remaining patients, after exclusion, included $21 \%$ with a prior history of retinal detachment, $8 \%$ with prior ruptured globe, $6 \%$ with glaucoma, $6 \%$ with pseudoexfoliation syndrome, and the remaining patients can be seen summarized in Table 1.

The stratification of accuracy of refractive outcomes is found in Table 3 with $63 \%$ of patients within $\pm 0.5 \mathrm{D}$ and $79 \%$ of patients within $\pm 1.0 \mathrm{D}$ of the refractive target. The

Table 3 Pre- and Post-Operative Refractive Data for Scleral Fixation of Akreos AO60 with Gore-Tex Suture

\begin{tabular}{|c|c|}
\hline Characteristics & Data \\
\hline Pre-operative BCVA, LogMAR, mean \pm SD & $0.67 \pm 0.64$ \\
\hline \multicolumn{2}{|l|}{ Final post-operative VA, LogMAR, mean \pm SD } \\
\hline BCVA & $0.16 \pm 0.18$ \\
\hline UCVA & $0.31 \pm 0.22$ \\
\hline $\begin{array}{l}\text { Pre-operative astigmatism, cylindrical } D \text {, } \\
\text { mean } \pm S D\end{array}$ & $1.09 \pm 0.89$ \\
\hline $\begin{array}{l}\text { Post-operative astigmatism, cylindrical } D \text {, } \\
\text { mean } \pm \text { SD }\end{array}$ & $0.85 \pm 0.84$ \\
\hline \multicolumn{2}{|l|}{$\begin{array}{l}\text { Post-operative Refraction, spherical } \\
\text { equivalent (D), Median }[\mathrm{IQR}]^{\ddagger}\end{array}$} \\
\hline \multicolumn{2}{|l|}{ Gender } \\
\hline Male & 0.31 [0.12 to 0.92$]$ \\
\hline Female & $0.38[0.25$ to 1.42$]$ \\
\hline & $P=0.07$ \\
\hline \multicolumn{2}{|l|}{ Reason for operation } \\
\hline Subluxed/dislocated crystalline lens & 0.21 [0.14 to 0.79$]$ \\
\hline Dislocated pseudophakic lens & $0.32[0.14$ to 1.07$]$ \\
\hline & $P=0.11$ \\
\hline \multicolumn{2}{|l|}{ Type of operation } \\
\hline PCIOL exchange & $0.38[0.26$ to 1.21$]$ \\
\hline Aphakic lens insertion & $0.29[0.14$ to 0.79$]$ \\
\hline \multirow[t]{2}{*}{ Lensectomy lens insertion } & $0.27[0.17$ to 0.79$]$ \\
\hline & $p>0.05$ \\
\hline \multicolumn{2}{|l|}{ Refractive Target, D, Median [IQR] } \\
\hline Based on SRK/T & $-0.24[-0.43$ to -0.09$]$ \\
\hline Based on Holladay & $-0.30[-0.54$ to -0.13$]$ \\
\hline \multicolumn{2}{|l|}{ Refractive accuracy, \% within: } \\
\hline $\pm 0.5 \mathrm{D}$ of target refraction & $63 \%$ \\
\hline $\pm 1.0 \mathrm{D}$ of target refraction & $79 \%$ \\
\hline$\pm \mathrm{I} .5 \mathrm{D}$ of target refraction & $94 \%$ \\
\hline $\pm 2.0 \mathrm{D}$ of target refraction & $98 \%$ \\
\hline
\end{tabular}

Note: ${ }^{\ddagger}$ Absolute value.

Abbreviations: BCVA, best-corrected visual acuity; SD, standard deviation; UCVA, uncorrected visual acuity; PCIOL, posterior chamber intraocular lens; D, diopter; SRK/T, Sanders-Retzlaff-Kraff theoretical; IQR, interquartile range. 
pre-operative average BCVA was $0.67 \pm 0.64 \operatorname{LogMAR}$ (20/93 Snellen). Average final post-operative BCVA was $0.16 \pm 0.18(20 / 28$ Snellen) and average final postop UCVA was $0.31 \pm 0.22$ (20/41 Snellen). The average preoperative astigmatism based on IOL master calculations was $1.09 \mathrm{D}$ (range 0 to $4.55 \mathrm{D}$ ). The average postoperative spherical equivalent was $-0.57 \mathrm{D}$. There was no significant difference in the type of Akreos surgery or reason for operation. The mean post-operative astigmatism was $0.24 \mathrm{D}$ less than the mean pre-operative astigmatism $(0.85 \mathrm{D}$, range 0 to $5.0 \mathrm{D})$. There were 38 eyes with refractive outcomes calculated by both SRK/T and Holladay formulas. The targets were found using IOL master with "in the bag" calculations. The difference between the formulas' spherical equivalent outcomes was not significant $(\mathrm{p}=0.53)$. The target calculated using the Holladay formula was slightly more myopic than the SRK/ $\mathrm{T}$ formula-derived target with a median difference -0.075 $\mathrm{D}(\mathrm{P}<0.0001)$.

A sensitivity analysis was performed with those patients with only a post-operative month 1 visit (6 patients) removed. The statistical significance of the results did not change.

Results for refractive outcomes based on intraoperative surgical techniques are listed in Table 4. There was no significant difference in refractive outcomes in clear corneal versus scleral tunnel or location of sclerotomy between $2.0 \mathrm{~mm}, 2.5 \mathrm{~mm}$, and $3.0 \mathrm{~mm}$ posterior to the corneoscleral limbus $(\mathrm{p}=0.61)$. The most frequent post-operative complication was cystoid macular edema (CME). Patients receiving an OCT within 3 months of surgery were found to have $\mathrm{CME}$ in $35 \%$ of cases, whereas patients who did not receive an OCT within 3 months of surgery were clinically diagnosed with $\mathrm{CME}$ at a rate of $16 \%$, however this was not significant $(p=0.0995)$. Other complications include transient ocular hypertension 10/63 (15.9\%), vitreous hemorrhage $6 / 63(9.5 \%)$, lens tilt $3 / 63(4.7 \%)$, suture exposure $3 /$ $63(4.7 \%)$, persistent corneal edema $3 / 63(4.7 \%)$, and retinal detachment $2 / 63$ (3.2\%). Patients with vitreous hemorrhage did have a significant deviation from the refractive target compared to those without $(\mathrm{P}=0.04)$.

\section{Discussion}

In this study, the refractive outcomes after secondary scleral-fixated IOL placement with a single lens, Akreos AO60, were examined. It is theorized that the 4 distinct points of fixation increase stability of the IOL, reducing tilt induced astigmatism and poor refractive outcomes, which
Table 4 Refractive Outcomes Based on Perioperative and PostOperative Surgical Factors

\begin{tabular}{|c|c|}
\hline Characteristics & Data \\
\hline $\begin{array}{l}\text { Main wound incision type, spherical equivalent } \\
\text { (SE, D), median [IQR] }\end{array}$ & \\
\hline Clear corneal incision (50) & $0.35[0.02$ to 1.0$]$ \\
\hline Scleral tunnel (13) & $\begin{array}{l}0.27[0.14 \text { to } 0.9] \\
P=0.53\end{array}$ \\
\hline $\begin{array}{l}\text { Location of sclerotomies from limbus, median } \\
{[\mathrm{IQR}] \ddagger}\end{array}$ & \\
\hline $2.0 \mathrm{~mm}$ & $0.25[0.17$ to 1.0$]$ \\
\hline $2.5 \mathrm{~mm}$ & $0.38[0.14$ to 1.07$]$ \\
\hline $3.0 \mathrm{~mm}$ & $\begin{array}{l}0.34[0.11 \text { to } 1.03] \\
P=0.80\end{array}$ \\
\hline
\end{tabular}

Post-operative complications (n), SE (D), median [IQR] ${ }^{\ddagger}$

Cystoid macular edema

\begin{tabular}{l|l} 
Yes (16) & 0.31 [0.14 to 0.68]
\end{tabular}

\begin{tabular}{l|l} 
No $(45)$ & 0.37 [0.17 to 1.11$]$
\end{tabular}

\begin{tabular}{|l|l|} 
& $P=0.57$ \\
\hline Ocular hypertension &
\end{tabular}

\begin{tabular}{l|l} 
Yes (9) & $0.18[0.14$ to 0.38$]$
\end{tabular}

$\begin{array}{lll}\text { No }(53) & 0.38[0.17 \text { to } \mathrm{I} . \mathrm{II}]\end{array}$

\begin{tabular}{|l|l|} 
& $P=0.17$ \\
\hline Vitreous hemorrhage &
\end{tabular}

\begin{tabular}{l|l} 
Yes (6) & $1.14[0.5$ to 1.65$]$
\end{tabular}

\begin{tabular}{l|l} 
No $(55)$ & $0.29[0.14$ to 0.92$]$
\end{tabular}

\begin{tabular}{|l|l|} 
& $P=0.04 *$ \\
\hline $\begin{array}{l}\text { Hypotony } \\
\text { Yes (6) }\end{array}$ & $0.79[0.37$ to 1.42$]$ \\
No (56) & $\begin{array}{l}0.31[0.14 \text { to } 0.92] \\
\end{array}$ \\
\hline $\begin{array}{l}\text { Lens tilt } \\
\text { Yes (3) }\end{array}$ & \\
No (59) & $0.12[0.1$ to 1.42$]$ \\
& $0.33[0.15$ to 1.0$]$ \\
\hline Corneal edema & $P=0.95$ \\
\hline Yes (3) & \\
No (59) & $0.79[0.32$ to 1.21$]$ \\
& $0.33[0.14$ to 1.0$]$ \\
\hline Retinal detachment & $P=0.35$ \\
Yes (2) & \\
No (6I) & $0.48[0.05$ to 0.9$]$ \\
& $0.33[0.17$ to 1.0$]$ \\
\hline
\end{tabular}

Notes: ${ }^{*} p<0.05$, ${ }^{\ddagger}$ Results expressed in absolute values.

Abbreviations: SE, spherical equivalent; $\mathrm{D}$, diopter; $\mathrm{mm}$, millimeter.

may be more common with certain secondary IOLs secured with 2-point fixation. ${ }^{8,9}$

There are significant challenges in examining the refractive data for secondary scleral-fixated intraocular 
lenses. There are often concurrent ocular comorbidities associated with aphakia or lens dislocation that may confound results. In particular, penetrating globe trauma with corneal stromal scarring can induce significant irregular astigmatism. ${ }^{10}$ Similarly, retinal detachment surgery with scleral buckle as well as glaucoma surgery with trabeculectomy can affect corneal topography. ${ }^{1-14}$ The goal of this study was to assess the refractive outcomes of scleral fixation of intraocular lenses in patients with good uncorrected visual acuity potential. Despite the strict exclusion criteria, the variability of cases was not limited, as there was still a large proportion with a history of trauma as well as prior vitrectomy.

There are multiple options for secondary lenses in the absence of capsular support, including anterior chamber IOL (ACIOL), iris fixation, traditional scleral fixation with polypropylene suture, glued IOL, and sutureless intrascleral fixation using a flanged haptic technique. ${ }^{15,16}$ As expected, each approach has its benefits and drawbacks. Refractive results of the scleral fixation of IOLs in the literature are limited and variable. ${ }^{17,18}$ However, in the authors' experience, there are refractive limitations in the two-point scleral fixation techniques that can affect effective lens position (ELP) and ultimately visual acuity. Because of difficulty in accurately estimating the ELP in these technically challenging procedures, many secondary IOL techniques offer minimal refractive predictability.

There are 2 series examining refractive results after secondary IOL placement with Gore-Tex suture. ${ }^{3,5}$ In both studies, there were inclusion of the Akreos AO60 IOL as well as another lens, the CZ70BD IOL and the MX60 IOL, respectively. Although there is use of GoreTex suture in all cases, there is a variance in the surgical techniques as well as the arrangement of the fixation vectors for the alternate IOLs. The Akreos AO60 has four eyelets in a rectangular arrangement, while the CZ70BD has 2 eyelets and a vaulted haptic, ${ }^{19}$ and the MX60 has two centrally located eyelets. ${ }^{20}$ It is unclear if these dissimilarities between the IOLs would lead to an incongruity in the propensity for tilt, and to heterogenous refractive results. In this study, only the single-lens Akreos AO60 was implanted.

Overall, the refractive outcomes were favorable with a high proportion of patients within $1 \mathrm{D}$ of the target. Additionally, the uncorrected visual acuity, in those patients with minimal pre-operative corneal astigmatism and a target of distance, was also satisfactory (Table 3). The average spherical equivalent was comparable to prior studies using this technique. ${ }^{5}$ In comparison to ACIOLs, this study demonstrated similar or superior outcomes. ${ }^{21,22}$ It was found that there was no significant difference in precision when comparing the Holladay and SRK/T formulas, although the Holladay formula for the selected lens gave a slightly more myopic target. The median difference in target of $-0.075 \mathrm{D}$ was statistically significant but would not be considered clinically significant.

There are variables in the procedure that are surgeon dependent. Yet, neither the location of the sclerotomy sites, nor main wound placement had an effect on the outcomes. The cause for this is unknown. It is possible that the residual laxity in the suture, which cannot be measured and can be variable, may impact the effective lens position. Given this result, it may well be beneficial for a more posterior location $(3.0 \mathrm{~mm}$ from the limbus vs $2.0 \mathrm{~mm}$ ) of the sclerotomy sites in order to protect from ciliary body hemorrhage or uveitis-glaucoma-hyphema syndrome. In this series, there was vitreous hemorrhage in $9.5 \%$ of cases and there were worse refractive outcomes in this group.

Some surgeons may reduce the power of the IOL if positioning the lens anteriorly. In this study, the choice of IOL power based on target and the operative notes did not reflect that there was reduction in lens power. Additionally, with the minimal difference between the target based on the IOL master and the outcome refraction, it appears there was not a significant deviation in calculation.

One of the most common complications in this study was cystoid macula edema at a rate of $26 \%$. This is higher than prior reported studies. ${ }^{1-3}$ The true rate of CME is unknown. It may be under reported as OCT of the macula, which may be needed to detect non-clinical CME, is not routinely performed on all patients in the post-operative period. Other complication rates were consistent with prior outcome studies on this technique.

Strengths of this study include the use of consecutive cases, large sample size, use of a single IOL model, and reporting of uncorrected visual acuity. A limitation of this study is that not all patients underwent topography in the pre- and post-operative period and thus astigmatism was inferred from IOL master and refraction. Many of the cases are performed by retina surgeons, who do not routinely obtain these measurements. Additionally, this was due to the retrospective nature of the study, and this level of refractive data not being clinically indicated on all patients. Unfortunately, there were some patients excluded due to not having a refraction in the post-operative period. 
This was in part due to some eyes having uncorrected vision of 20/30 or better, and the patients not requesting distance correction. If assumed that this cohort may have a low refractive error, then the post-operative spherical equivalent may have been even closer to the target than reported in this study. Future studies may examine final effective lens position, as well as the degree of tilt, with optical coherence tomography (OCT).

In conclusion, the post-operative refractive outcomes as well as the uncorrected visual acuity after secondary implantation with Akreos AO60 are favorable in eyes with good visual potential.

\section{Ethics}

Patient consent to review their medical records was waived due to the retrospective nature of the review. The data were anonymized and maintained with confidentiality.

\section{Presentations}

American Society for Cornea and Refractive surgeons, San Diego, 2019.

Association for Vision in Research and Ophthalmology, B.C., Canada, 2019.

\section{Funding}

Supported in part by NIH Center Core Grant P30EY014801 (Bethesda, Maryland) and Research to Prevent Blindness Unrestricted Grant to UM.

\section{Disclosure}

JS serves as a consultant for Alcon, Alimera Sciences, Regeneron, Dorc, and Oxurion. LJH serves as a consultant for Alimera Science. JHT serves as a consultant for Bausch \& Lomb. SHY serves as a consultant for Carl Zeiss Meditec, Dompe, and Avedro; reports grants from Avellino and Senju Pharmaceutical. TAA serves as a consultant for Adverum Biotechnologies, Allergan, Allegro Ophthalmics, Beaver Visitec, Clearside Biomedical, Eyepoint Pharmaceuticals, Genentech, Janssen Biotech, Notal Vision, Novartis, RegenexBio, Santen, and Valeant. JAF serves as a consultant for Dutch Ophthalmic and Carl Zeiss Meditec; a consultant and research support for Allergan and Novartis. PJP reports grants from the National Institutes of Health National Eye Institute and Research to Prevent Blindness. EAV reports grants from NIH Center Core Grant P30EY014801 and Research to Prevent Blindness Unrestricted Grant, during the conduct of the study. BKW Jnr reports personal fees from Genentech and Castle
Biosciences, outside the submitted work. KD serves as a consultant for Alcon, Johnson and Johnson, Eyevance, Kala Pharmaceuticals, Carl Zeiss Pharmaceuticals, and Tissue Tech. The authors report no other conflicts of interest in this work.

\section{References}

1. Khan MA, Gupta OP, Smith RG, et al. Scleral fixation of intraocular lenses using Gore-Tex suture: clinical outcomes and safety profile. $\mathrm{Br}$ $J$ Ophthalmol. 2016;100(5):638-643. doi:10.1136/bjophthalmol2015-306839

2. Patel NA, Shah P, Yannuzzi NA, et al. Clinical outcomes of 4-point scleral fixated 1-piece hydrophobic acrylic equiconvex intraocular lens using polytetrafluoroethylene suture. Clin Ophthalmol. 2018;12:2145-2148. doi:10.2147/OPTH.S174211

3. Botsford BW, Williams AM, Conner IP, Martel JN, Eller AW. Scleral fixation of intraocular lenses with gore-tex suture: refractive outcomes and comparison of lens power formulas. Ophthalmol Retina. 2019;3(6):468-472. doi:10.1016/j.oret.2019.02.005

4. Khan MA, Gupta OP, Pendi K, et al. Pars Plana vitrectomy with anterior chamber versus gore-tex sutured posterior chamber intraocular lens placement: long-term outcomes. Retina. 2019;39 (5):860-866. doi:10.1097/IAE.0000000000002042

5. Su D, Stephens JD, Obeid A, et al. Refractive outcomes after pars plana vitrectomy and scleral fixated intraocular lens with gore-tex suture. Ophthalmol Retina. 2019;3(7):548-552. doi:10.1016/j. oret.2019.02.012

6. Khan MA, Samara WA, Gerstenblith AT, et al. Combined pars plana vitrectomy and scleral fixation of an intraocular lens using gore-tex suture: one-year outcomes. Retina. 2018;38(7):1377-1384. doi:10. 1097/IAE.0000000000001692

7. Pager CK. Expectations and outcomes in cataract surgery: a prospective test of 2 models of satisfaction. Arch Ophthalmol. 2004;122(12):1788-1792. doi:10.1001/archopht.122.12.1788

8. Stem MS, Todorich B, Woodward MA, Hsu J, Wolfe JD. Scleralfixated intraocular lenses: past and present. J Vitreoretin Dis. 2017;1 (2):144-152. doi:10.1177/2474126417690650

9. Weikert MP, Golla A, Wang L. Astigmatism induced by intraocular lens tilt evaluated via ray tracing. J Cataract Refract Surg. 2018;44 (6):745-749. doi:10.1016/j.jcrs.2018.04.035

10. Jain S, Azar DT, Pineda R. Management of astigmatism after corneal trauma. Int Ophthalmol Clin. 2002;42(3):47-55.

11. Okada Y, Nakamura S, Kubo E, Oishi N, Takahashi Y, Akagi Y. Analysis of changes in corneal shape and refraction following scleral buckling surgery. Jpn J Ophthalmol. 2000;44(2):132-138. doi:10.1016/S0021-5155(99)00183-5

12. Weinberger D, Lichter H, Loya N, et al. Corneal topographic changes after retinal and vitreous surgery. Ophthalmology. 1999;106 (8):1521-1524. doi:10.1016/S0161-6420(99)90447-5

13. Delbeke H, Stalmans I, Vandewalle E, Zeyen T. The effect of trabeculectomy on astigmatism. J Glaucoma. 2016;25(4):e308-312. doi:10.1097/IJG.0000000000000236

14. Alvani A, Pakravan M, Esfandiari H, Safi S, Yaseri M, Pakravan P. Ocular biometric changes after trabeculectomy. J Ophthalmic Vis Res. 2016;11(3):296-303. doi:10.4103/2008-322X.188399

15. Yamane S, Inoue M, Arakawa A, Kadonosono K. Sutureless 27-gauge needle-guided intrascleral intraocular lens implantation with lamellar scleral dissection. Ophthalmology. 2014;121(1):61-66. doi:10.1016/j.ophtha.2013.08.043

16. Mohan S, John B, Rajan M, Malkani H, Nagalekshmi SV, Singh S. Glued intraocular lens implantation for eyes with inadequate capsular support: analysis of the postoperative visual outcome. Indian J Ophthalmol. 2017;65(6):472-476. doi:10.4103/ijo.IJO_375_16 
17. Abbey AM, Hussain RM, Shah AR, Faia LJ, Wolfe JD, Williams GA. Sutureless scleral fixation of intraocular lenses: outcomes of two approaches. The 2014 Yasuo Tano Memorial Lecture. Graefes Arch Clin Exp Ophthalmol. 2015;253(1):1-5.

18. Sindal MD, Nakhwa CP, Sengupta S. Comparison of sutured versus sutureless scleral-fixated intraocular lenses. J Cataract Refract Surg. 2016;42(1):27-34. doi:10.1016/j.jcrs.2015.09.019

19. Bonnell AC, Mantopoulos D, Fine HF, Shah SP, Wheatley HM, Prenner JL. One-year outcomes of a novel surgical approach for fixation of a posterior chamber intraocular lens using gore-tex suture. Retina. 2019.
20. Yang JM, Yoon KC, Ji YS. Transscleral fixation of single-piece foldable acrylic lens with eyelets at the optic-haptic junction. Can J Ophthalmol. 2015;50(5):367-372. doi:10.1016/j.jcjo.2015.07.006

21. Waddell KM, Reeves BC, Johnson GJ. A comparison of anterior and posterior chamber lenses after cataract extraction in rural Africa: a within patient randomised trial. $B r J$ Ophthalmol. 2004;88 (6):734-739. doi:10.1136/bjo.2003.031187

22. Brunin G, Sajjad A, Kim EJ, et al. Secondary intraocular lens implantation: complication rates, visual acuity, and refractive outcomes. J Cataract Refract Surg. 2017;43(3):369-376. doi:10.1016/j.jcrs.2016.12.024

\section{Publish your work in this journal}

Clinical Ophthalmology is an international, peer-reviewed journal covering all subspecialties within ophthalmology. Key topics include: Optometry; Visual science; Pharmacology and drug therapy in eye diseases; Basic Sciences; Primary and Secondary eye care; Patient Safety and Quality of Care Improvements. This journal is indexed on PubMed

Submit your manuscript here: https://www.dovepress.com/clinical-ophthalmology-journal
Central and CAS, and is the official journal of The Society of Clinical Ophthalmology (SCO). The manuscript management system is completely online and includes a very quick and fair peer-review system, which is all easy to use. Visit http://www.dovepress.com/ testimonials.php to read real quotes from published authors. 